\title{
Unmet medical needs in the treatment of atopic dermatitis in infants: An Expert consensus on safety and efficacy of pimecrolimus
}

\author{
Thomas Luger $^{1}$ (D) | Matthias Augustin ${ }^{2}$ | Julien Lambert ${ }^{3}$ | Carle Paul $^{4}$ | \\ Carlo Pincelli $^{5}$ | Antonio Torrelo ${ }^{6}$ | Christian Vestergaard ${ }^{7}$ | Ulrich Wahn ${ }^{8}$ \\ Thomas Werfel ${ }^{9}$
}

\author{
${ }^{1}$ Department of Dermatology, University of \\ Münster, Münster, Germany \\ ${ }^{2}$ University Medical Centre Hamburg- \\ Eppendorf, Hamburg, Germany \\ ${ }^{3}$ Department of Dermatology, University \\ Hospital of Antwerp, University of Antwerp, \\ Antwerp, Belgium \\ ${ }^{4}$ Department of Dermatology, Toulouse \\ University, Toulouse, France \\ ${ }^{5}$ Laboratory of Cutaneous Biology, \\ Department of Surgical, Medical, Dental \\ and Morphological Sciences, University of \\ Modena and Reggio Emilia, Modena, Italy \\ ${ }^{6}$ Department of Dermatology, Hospital Infantil \\ Universitario Niño Jesús, Madrid, Spain \\ ${ }^{7}$ Department of Dermatology, Aarhus \\ University Hospital, Aarhus, Denmark \\ ${ }^{8}$ Department for Pediatric Pneumology and \\ Immunology, Charité Medical University, \\ Berlin, Germany \\ ${ }^{9}$ Department of Dermatology and Allergy, \\ Hannover Medical School, Hannover, \\ Germany
}

\section{Correspondence}

Thomas Luger, Department of Dermatology, University of Münster, Von-Esmarch-Straße 58, 48149 Münster, Germany.

Email: luger@uni-muenster.de

Funding information

The writing/editorial support was funded by Meda, a Mylan company.

\begin{abstract}
Atopic dermatitis (AD) is a common skin disease during infancy, which imposes a considerable burden on patients, their families, and the society, requiring effective treatment options that result in rapid and sustained symptom relief. Additionally, early treatment may prevent the development of atopic comorbidities by restoring the skin barrier. Currently, topical standard-of-care for AD in infants includes emollients and topical corticosteroids (TCS) to treat and reduce the risk of flares. However, only few have been approved for infants and long-term maintenance therapy with TCS is not indicated due to potential local and systemic side effects, including skin atrophy. Accordingly, the recently updated European guidelines for treatment of AD recommend topical calcineurin inhibitors ( $\mathrm{TCls}$ ) for long-term use, treatment of sensitive skin areas, and for use in the pediatric population. Evidence on the use of TCls for infants has almost been exclusively collected for pimecrolimus, with $>4000$ infants evaluated in clinical trials, consistently confirming that pimecrolimus is a safe and effective treatment for infants with AD. Nevertheless, its use is still restricted in most countries to children above the age of 2 years due to initial and mostly theoretical safety concerns. Based on a careful review of the available evidence of clinical trials, post-marketing surveillance, and epidemiological studies, an Expert Panel of European dermatologists and pediatric allergologists concluded that these safety concerns are no longer valid. Therefore, pimecrolimus offers a safe and effective alternative to TCS in infants aged 3 months and above, and labeling restrictions in this age group are no longer justified.
\end{abstract}

\section{KEYWORDS}

atopic dermatitis, efficacy, infant, pimecrolimus, safety

Editor: Motohiro Ebisawa

\begin{abstract}
Abbreviations: AD, atopic dermatitis; AEs, adverse events; CI, confidence interval; EASI, Eczema Area and Severity Index; EMA, European Medicines Agency; FDA, Food and Drug Administration; HR, hazard ratio; IGA, Investigator's Global Assessment; LoQ, limit of quantification; MAS, Multicenter Allergy Study; NMSC, nonmelanoma skin cancer; OL, open-label; OLE, open-label extension; OR, odds ratio; PEER, Pediatric Eczema Elective Registry; PIM, pimecrolimus; QoL, quality of life; RCT, randomized controlled trial; RR, relative risk; SAM, Study of the Atopic March; TAC, tacrolimus; TBSA, total body surface area; TCls, topical calcineurin inhibitors; TCL, T-cell lymphoma; TCS, topical corticosteroids.

This is an open access article under the terms of the Creative Commons Attribution-NonCommercial License, which permits use, distribution and reproduction in any medium, provided the original work is properly cited and is not used for commercial purposes.

(c) 2020 The Authors. Pediatric Allergy and Immunology published by European Academy of Allergy and Clinical Immunology and John Wiley \& Sons Ltd
\end{abstract}




\section{1 | BACKGROUND}

Atopic dermatitis (AD) is one of the most common chronic inflammatory dermatoses, occurring often in families with atopic predisposition and other atopic diseases. ${ }^{1}$ Pruritus and eczematous lesions are important clinical manifestations of $A D$, with pruritus being the most debilitating symptom of the disease. ${ }^{2-4}$ The distribution and morphology of the lesions vary with age, and especially during infancy, sensitive skin areas, such as the face, neck, and scalp, are affected. ${ }^{1,5}$ Although the pathophysiology of AD is not completely understood, accumulating evidence suggests a complex interplay between genetic, immunological, and environmental factors contributing to impaired epidermal barrier function and allergic inflammation., ${ }^{1,5-8}$ The worldwide prevalence of $A D$ ranges between $10 \%$ and $20 \%$ in the pediatric population, depending on the geographic region. ${ }^{9,10}$ Among patients with $A D$, the majority have an onset in infancy, with about $73 \%$ presenting symptoms before the age of 2 years, underscoring the importance of early effective and safe management in the infant age group. ${ }^{7,11,12}$ Furthermore, the incidence in infants continued to increase during recent years. ${ }^{13}$ Persistence of $A D$ is also prolonged with age of onset, as patients who were diagnosed between the ages of 0 to 1 year or between the ages of 6 to 11 years had a median persistence of AD of 3 or 12.5 years, respectively. ${ }^{14}$ Currently, AD cannot be cured and management focuses on restoring the disturbed epidermal barrier function and tempering the inflammatory skin responses to ultimately treat and reduce the risk of flares in the long term. ${ }^{15}$ The recently published consensus-based European guidelines for treatment of $A D$, recommend topical corticosteroids (TCS) as first-line anti-inflammatory therapy in infants with mild-to-moderate AD. ${ }^{15}$ However, TCS are associated with several limitations due to potential local side effects, including skin infections, impairment of the epidermal barrier function, and skin atrophy, which limit their use for treatment of sensitive skin areas. ${ }^{15,16}$ Additionally, percutaneous absorption of TCS through the disrupted skin may lead to systemic exposure and subsequent growth impairment. ${ }^{16}$ As a result of these safety limitations, adherence to TCS is often poor due to corticophobia. ${ }^{15,17}$ The topical calcineurin inhibitors (TCls)-pimecrolimus $1 \%$ cream (Elidel ${ }^{\circledR}$, Meda) and tacrolimus $0.03 \%$ and $0.1 \%$ ointment (Protopic ${ }^{\circledR}$, Astellas)-are another class of anti-inflammatory drugs, which are indicated for mild-to-moderate and moderate-to-severe $\mathrm{AD}$, respectively. ${ }^{18-21} \mathrm{TCl}$ s have a more selective mechanism of action compared to TCS and do not cause impairment of the epidermal barrier function and skin atrophy. ${ }^{15,22,23}$ Therefore, the European guidelines for treatment of AD recommend $\mathrm{TCls}$ for use in sensitive skin areas as well as for long-term treatment. ${ }^{15}$ Evidence from clinical trials on the use of TCls for the treatment of $A D$ in infants mostly exists for pimecrolimus. Based on this evidence, pimecrolimus is approved in infants aged $\geq 3$ months in 10 countries (Elidel ${ }^{\circledR}$ [pimecrolimus] cream 1\%, Prescribing Information [Australia, Brazil, Canada, India, Indonesia, Israel, New Zealand, Philippines, Russia, and Thailand]). However, pimecrolimus is currently not approved in Europe and the United States (US) in children below the age of 2 years due to initial safety concerns. In 2006, the

\section{Key Messages}

This narrative review compiles evidence that has been generated during the last 20 years on the use of pimecrolimus $1 \%$ cream in infants for the treatment of atopic dermatitis. The authors believe this work is of interest to the readers of Pediatric Immunology \& Allergy, since use of pimecrolimus is still restricted to children aged 2 years and above in most countries, including European countries. According to the evidence and the opinion of the Experts, there is currently no reason to support this restriction any longer. The Experts hope this review will convince the readers to initiate treatment of atopic dermatitis already during infancy and to consider topical pimecrolimus as an alternative to topical corticosteroids for the treatment of atopic dermatitis in infants aged 3 months and above.

Food and Drug Administration (FDA) added a black-box warning to the TCls' labels to emphasize that long-term use has not been established, warning about a theoretical increased risk of lymphoma and skin malignancies, and indicating that use of $\mathrm{TCl}$ in infants is not approved. ${ }^{18}$ In the same year, the European Medicines Agency (EMA) limited the use of TCls to second-line treatment of AD following a safety review. ${ }^{19}$ During the last 20 years, both the short- and long-term safety of pimecrolimus for the treatment of AD in infants has been extensively evaluated. Furthermore, a previous recommendation from an international group of dermatologists already concluded in 2015 that use of pimecrolimus should no longer be restricted to children above the age of 2 years. ${ }^{24}$ Here, we present the findings from a virtual meeting held in May 2020 attended by nine European Experts in AD. An updated consensus guidance was developed based on a review of the latest available evidence combined with the opinion of the Expert Panel on the prevailing medical need for safe and effective treatment options in infants with $A D$. This review aims to provide the rationale behind the high need to initiate treatment of AD during infancy and to update the previous consensus guidance on the use of pimecrolimus in infants between 3 months and 2 years of age.

\section{I RATIONALE FOR EARLY TREATMENT INITIATION OF AD DURING INFANCY}

Atopic dermatitis is not a stand-alone disorder, but is associated with a variety of comorbidities, including progression of atopic manifestations, known as the atopic march. Although results on the existence of a sequential atopic march have been inconsistent, a growing body of evidence supports that children with $A D$ are at high risk of developing various atopic comorbidities including food allergy, asthma, and allergic rhinitis. ${ }^{25-32}$ The most apparent association is found between $A D$ and sensitization to food allergens. ${ }^{25,28,29,32}$ The mechanism behind the 
TABLE 1 Overview of clinical studies evaluating topical use of pimecrolimus in infants. Studies reporting on the same patients were grouped

\begin{tabular}{|c|c|c|c|}
\hline Study & Age group & Study design & Disease severity \\
\hline $\begin{array}{l}\text { Kaufman et al }(2004)^{47} \text { and Staab } \\
\text { et al }(2005)^{52}\end{array}$ & $3-23$ mo & $\begin{array}{l}\text { PIM }(n=129) \text { or vehicle }(n=66) \text { for } 4 \text { wk in double-blind } \\
\text { RCT, followed by OL treatment with PIM for } 12 \text { wk, } \\
\text { then } 4 \text {-wk follow-up without treatment }\end{array}$ & Mild to very severe \\
\hline $\begin{array}{l}\text { Kapp et al (2002), }{ }^{48} \text { Papp et al (2004), } \\
\text { Papp et al (2005) } \\
\text { et al }(2006)^{53}\end{array}$ & $3-23 \mathrm{mo}$ & $\begin{array}{l}\text { PIM }(n=204) \text { or vehicle }(n=47) \text { for } 1 \text { y in double-blind } \\
\text { RCT, followed by } 1 \text {-y OLE consisting of } 76 \text { patients who } \\
\text { received pimecrolimus for } 2 \text { y }\end{array}$ & Mild to very severe \\
\hline Ho et al $(2003)^{51}$ & $3-23$ mo & $\begin{array}{l}\text { PIM }(n=123) \text { or vehicle }(n=63) \text { for } 6 \text { wk in double-blind } \\
\text { RCT, followed by } 20 \text {-wk OLE with PIM }\end{array}$ & Mild to moderate \\
\hline Sigurgeirsson et al (2015) ${ }^{59}$ & $\geq 3-<12 \mathrm{mo}$ & $\begin{array}{l}\text { PIM ( } n=1205) \text { or TCS }(n=1213) \text { for } 5 \text { y in randomized, } \\
\text { OL, parallel-group study }\end{array}$ & Mild to moderate \\
\hline $\begin{array}{l}\text { Schneider et al }(2016)^{31} \text { and Spergel } \\
\text { et al }(2015)^{34}\end{array}$ & 3-18 mo & $\begin{array}{l}\text { PIM }(n=543) \text { or vehicle }(n=544) \text { for } 3 y \text { in double-blind } \\
\text { RCT, followed by OLE, including only patients without } \\
\text { diagnosis of asthma, who were treated with PIM for } 3 y \\
\text { or until the age of } 6 y\end{array}$ & Mild to very severe \\
\hline
\end{tabular}

Abbreviations: mo, months; OL, open-label; OLE, open-label extension; PIM, pimecrolimus; RCT, randomized controlled trial; TCS, topical corticosteroids; wk, weeks; y, years.

increased susceptibility to food allergy in patients with $A D$ remains to be deciphered and is multifactorial, such as the pathogenesis of $A D$ itself. ${ }^{29,32,33}$ Regardless of the mechanism, earlier onset and more severe disease are important risk factors for the development of usually multiple food allergies, arguing for preventative treatment strategies of $A D$ during infancy. ${ }^{28,34,35}$ To address this hypothesis, a recent multicenter, randomized controlled trial (RCT), including 1394 newborns, assessed the impact of daily emollient use during the first year of life to prevent $A D$ as well as food allergy and other atopic comorbidities. ${ }^{36}$ Unlike other reports, emollients were not able to prevent $A D$, indicating that more effective treatment options may be needed to restore the skin barrier in infants who are at high risk to develop $A D$ and subsequent atopic comorbidities. ${ }^{36}$

The classical course of the atopic march, which progresses from $A D$ to food allergy, allergic rhinitis, and ultimately asthma, has been challenged over the years. However, there is an undoubtable association between these atopic comorbidities, as already has been discussed for $A D$ and food allergy. Although not every child with $A D$ will be sensitized to inhalant allergens, several birth cohort studies have demonstrated that onset of AD during infancy, AD severity, and parental atopy are strong predictors to develop allergic rhinitis and asthma later in life. ${ }^{12,26,27,37}$ The German Multicenter Allergy Study (MAS) is until now the longest birth cohort study, which followed up patients until the age of 20 years. ${ }^{27,37}$ The MAS demonstrated that $A D$, asthma, and allergic rhinitis particularly coexist as a multimorbidity in patients who have parents with allergies, implying the importance of yet to be fully determined genetic factors. ${ }^{27,38}$ More longitudinal studies are still warranted to understand if treatment at first signs and symptoms during infancy may prevent the allergic multimorbidity, especially in those who are at risk to develop atopy.

Additionally, AD was found to be associated with comorbidities beyond the atopic march, including cardiovascular and neuropsychiatric disorders. ${ }^{39-41}$ The latter comorbidity is mostly driven by the impact of $A D$ on the whole family, particularly so on the quality of life (QoL) of young children and their caregivers. ${ }^{2,39,42}$ Itching and scratching are the most distressing early symptoms of the disease, which can lead to sleeplessness, psychological disorders, social isolation, and overall poor QoL of patients and their families. ${ }^{3,43}$ Similar to atopic comorbidities, QoL decreases when the severity of AD increases, emphasizing the need for treatments that rapidly and sustainably relieve pruritus. ${ }^{2}$

There is also a considerable economic impact of $A D$ on patients, patients' families, and payers. Direct costs of AD are mostly related to prescriptions, physician visits, hospital costs, and pharmacy costs. ${ }^{2}$ These direct costs were calculated to be as high as €927 per patient per year by a recent cross-sectional study performed in nine European countries and pose a significant economic burden to the patient that is more pronounced compared with other chronic diseases, such as psoriasis and rheumatoid arthritis. ${ }^{44}$ Furthermore, $A D$ is associated with a variety of indirect costs due to decreased productivity and work absenteeism, which are related to the social and psychological burden of the disease. ${ }^{2,45}$ Paradoxically, the prevalence of $A D$ was reported to correlate with the socioeconomic status, whereas patients with severe AD were found to have less educational attainment resulting in a lower annual income. ${ }^{45,46}$ Consequently, improved care for AD would allow substantial savings in the short and long term for both patients and the society. Therefore, early treatment of $A D$ is not only essential in treating the skin disease itself to prevent worsening, but also to prevent the development of atopic comorbidities and most importantly decrease the significant burden of AD on the entire family and the society as early as possible.

\section{3 | EFFICACY OF PIMECROLIMUS IN INFANTS}

The efficacy of pimecrolimus for the treatment of $A D$ in infants has been extensively evaluated in multiple vehicle-controlled pivotal trials 
(Table 1). These trials have consistently demonstrated that topical pimecrolimus treatment results in effective long-term control of $A D$ in infants. ${ }^{47-51}$ Twice-daily application of pimecrolimus in infants effectively reduced the risk for flares compared with vehicle, with $67.6 \%$ vs $30.4 \%$ of patients completing 6 months without flares $(P<.001)$, resulting in an absolute risk reduction of $37.2 \%$, which was independent of baseline severity. ${ }^{48}$ Additionally, the mean Eczema Area and Severity Index (EASI) was already reduced by approximately $70 \%-80 \%$ after 4 weeks of pimecrolimus treatment, while there was no symptom relief at this time point for infants who were treated with vehicle control. ${ }^{47,51}$ Furthermore, this response was irrespective of disease severity and significant even for infants with very severe disease (Investigator's Global Assessment $[$ IGA] $\geq 4) .{ }^{47}$ The earliest significant reduction in EASI was reported from day 4 onwards, with a reduction of $38.5 \%$ and $17.6 \%$ after 4 days of pimecrolimus and vehicle treatment, respectively $(P<.001) .{ }^{47}$ Importantly, the early and sustained treatment success (IGA 0 or 1) observed in the head and neck area was similar to that of the whole body. A rapid response in sensitive skin areas is especially important in infants who mostly have a sensitive skin structure to decrease the disease burden as early as possible. ${ }^{47}$ Furthermore, disease control with pimecrolimus was proven to be long term, with approximately $70 \%$ of patients having minimal or no disease, as assessed by the IGA score and EASI, after 2 years of intermittent pimecrolimus treatment. ${ }^{49}$ Similar to the reductions seen in EASI and IGA scores, pimecrolimus effectively relieved pruritus, which was associated with significant improvements in the QoL and sleep behavior of the infant. Already within the first week of use, $70 \%$ of infant patients reported absence of mild pruritus compared to about half of the patients treated with vehicle. ${ }^{47-49,51-53}$ Also, parents experienced significant improvements in psychosomatic well-being, social life, confidence in medical treatment, and emotional coping after 4 weeks of treatment of their infants. ${ }^{52}$ These improvements in QoL of parents were found to be sustained up to 1 year of treatment and probably thereafter, as they coincided with long-term disease control of their infants. ${ }^{53}$ Although not evaluated in this study, such impact on QoL presumably also decreases the substantial economic burden of the disease. In the vehicle-controlled trials, use of pimecrolimus was found to decrease throughout long-term treatment upon clearance of symptoms, but importantly discontinuation was not associated with rebound flares, as has been described for TCS. ${ }^{47,49,54}$ Pimecrolimus treatment also had a steroid-sparing effect in the infant, which was reflected by a decrease in overall use and an increased time to first use of TCS as well as a reduced number of days on TCS therapy. ${ }^{48,50}$

Head-to-head comparisons between pimecrolimus and tacrolimus in the pediatric population were assessed in two RCTs, which evaluated both treatments in children of 2 to 17 years of age. ${ }^{55,56}$ These two trials were also included in a meta-analysis, demonstrating that pimecrolimus and tacrolimus have comparable efficacy in children with AD. ${ }^{57}$ However, to the best of our knowledge, there is only one 24-month open-label phase II clinical trial evaluating safety and efficacy of tacrolimus in 50 infants below the age of 2 years, indicating additional studies are needed to evaluate tacrolimus for the infant indication. ${ }^{58}$
To support the use of pimecrolimus as an alternative treatment to TCS in infants, the PETITE study was designed to compare the long-term safety and efficacy of TCS and pimecrolimus for the treatment of infants with AD in a real-world setting. ${ }^{59}$ In total, 2418 infants aged between 3 and 12 months were randomized to receive either pimecrolimus ( $n=1205$ ) or mild-to-moderate potency TCS $(n=1213) .{ }^{59}$ However, short-term use of TCS was allowed in case disease flares could not be controlled by pimecrolimus treatment. The PETITE study confirmed the previous results from the vehicle-controlled trials, showing that pimecrolimus relieved symptoms in more than $50 \%$ of patients already after 3 weeks of treatment. The onset of disease control was comparable between pimecrolimus and TCS, and treatment with both anti-inflammatory drugs resulted in almost complete clearance of symptoms in more than $85 \%$ of patients after 1.5 years of intermittent treatment. Accordingly, less than $5 \%$ of body surface area was affected in week 3 , with no eczematous lesions after 1.5 years of treatment in both groups which was maintained until the end of the study. ${ }^{59}$ Importantly, pimecrolimus was steroid-sparing, as $36 \%$ of patients in the pimecrolimus group did not use any TCS during the 5 years follow-up period. ${ }^{59}$ Whether or not the reduced need for TCS improves treatment adherence by overcoming concerns related to corticophobia remains to be formally demonstrated. However, it is well-established that use of TCS is causing epidermal thinning and skin atrophy, while pimecrolimus can restore certain aspects of the epidermal barrier. ${ }^{23}$ As infants overall have a sensitive structure of the skin, this is an additional factor favoring long-term use of pimecrolimus over TCS for infants with $A D$.

So far, the Study of the Atopic March (SAM) is the only RCT that examined the impact of pimecrolimus vs vehicle treatment on the development of atopic comorbidities in infants with AD. ${ }^{31,34}$ This initial study found no effect of early pimecrolimus treatment on the development of atopic comorbidities which may be at least partially attributed to the unexpectedly high discontinuation rate (48\%) due to the fact that the trial was conducted just after implementation of the black-box warning for pimecrolimus. ${ }^{31,34}$ Nevertheless, rates of food allergies, asthma, and allergic rhinitis were all lower than previously reported, not excluding an effect of early treatment. ${ }^{31}$ Additionally, most infants were not presenting with severe disease and rescue therapy with TCS was permitted in both treatment groups, which may have compromised the results. ${ }^{31}$ Due to the aforementioned limitations, it remains currently unclear whether early intervention with pimecrolimus for treatment of $A D$ in infants may prevent the development of atopic comorbidities.

\section{I PHARMACOKINETICS OF PIMECROLIMUS IN INFANTS}

Initial safety concerns were related to the potential systemic absorption of pimecrolimus. However, evidence from experiments in minipigs showed that the systemic bioavailability of pimecrolimus was transient and negligible, making the risk for systemic side effects not 
relevant. ${ }^{60}$ Furthermore, the penetration and permeation profile of pimecrolimus was superior compared to other treatments for AD. Whereas drug concentrations of pimecrolimus in human skin were of the same order of magnitude as tacrolimus and TCS, permeation was 9-10 and 70-110 fold lower than tacrolimus and TCS, respectively, predicting lower systemic exposure. ${ }^{61}$ The pharmacokinetic (PK) profile of pimecrolimus was evaluated in six studies, which enrolled a total of 41 infants treated with pimecrolimus for 3 weeks (Table 2). Pimecrolimus blood concentrations were below the limit of quantification (LoQ) in the majority of samples, which was either 0.1 or $0.5 \mathrm{ng} / \mathrm{mL}$, depending on the assay used. ${ }^{62-66}$ In the remaining blood samples, the blood concentration of pimecrolimus was below $2 \mathrm{ng} / \mathrm{mL}$, with some exceptional outliers that were just above this limit. One study evaluated blood samples of infants aged between 5.7-11.9 months over a 1-year period of intermittent pimecrolimus treatment. ${ }^{64}$ Importantly, this study found no accumulation of pimecrolimus in infants with moderate-to-severe $A D$, consistently showing minimal systemic exposure even in the long term. The impact of the total body surface area (TBSA) affected was also found to be minimal, and the difference between patients with $90 \%$ and $10 \%$ of TBSA affected was not greater than $0.74 \mathrm{ng} / \mathrm{mL} .{ }^{63}$ These findings were also supported by another study, which enrolled infants with a maximum TBSA affected of $92 \%$, but systemic pimecrolimus concentrations remained below $2.26 \mathrm{ng} / \mathrm{mL}$ in all infants after 3 weeks of treatment. ${ }^{66}$ These concentrations are far below the maximum blood concentration $(54.5 \mathrm{ng} / \mathrm{mL})$ observed in adult patients with psoriasis treated orally with $30 \mathrm{mg}$ twice daily of pimecrolimus for 4 weeks, a dose that was also well-tolerated in these patients. ${ }^{63}$ An analysis of pimecrolimus blood concentrations in infants compared to older children ( $>24$ months of age) demonstrated that infants were not a higher risk for systemic exposure of pimecrolimus, and that blood concentrations of pimecrolimus remained below the LoQ (ie, $<0.5 \mathrm{ng} / \mathrm{mL}$ ) in the majority of patients, irrespective of age. ${ }^{67}$ Overall, the favorable penetration and permeation profile of pimecrolimus seen in minipigs together with the minimal systemic exposure found in the PK studies support that use of pimecrolimus in infants is safe, regardless of the TBSA affected and duration of treatment.

\section{5 | SAFETY OF PIMECROLIMUS IN INFANTS}

The favorable safety profile of pimecrolimus in infants has been demonstrated in the above described vehicle-controlled trials (Table 1)..$^{31,47-49,51,52}$ Four of these trials were also evaluated in a previously pooled safety analysis. ${ }^{67}$ In this safety analysis, a total of 495 pimecrolimus-treated infants were compared with a total of 193 infants who were treated with vehicle. ${ }^{67}$ Although results of this analysis may have been confounded by larger patient numbers in the pimecrolimus treatment group, rates of adverse events (AEs) were similar between pimecrolimus and vehicle, except for teething which was more commonly observed in pimecrolimus-treated infants. ${ }^{67}$ All other AEs were disorders typically encountered during childhood, such as nasopharyngitis, pyrexia, upper respiratory tract infections, and bronchitis. ${ }^{67}$ Burning and erythema were the most frequently reported application site reactions, occurring in less than $1 \%$ of infants treated with pimecrolimus. ${ }^{67}$ Consistent with the low systemic exposure of pimecrolimus in infants (Table 2), the pooled safety analysis confirmed that use of pimecrolimus is not associated with immunosuppression. ${ }^{67}$ Accordingly, the incidence of non-skin infections was comparable between pimecrolimus and vehicle treatment groups (relative risk: 1.015; 95\% confidence interval [Cl] 0.88-1.18). The incidence rates of bacterial, fungal, parasitic, and viral skin infections were also not altered by pimecrolimus treatment. ${ }^{67}$ To further evaluate the impact of topical pimecrolimus on the developing immune system, seropositivity rates upon vaccination were assessed in 91 infants, who had applied pimecrolimus for a median number of

TABLE 2 Overview of pharmacokinetic studies evaluating pimecrolimus in the pediatric population

\begin{tabular}{|c|c|c|c|c|c|c|}
\hline Study & Duration & $\begin{array}{l}\text { Number of } \\
\text { patients }\end{array}$ & Age group & $\begin{array}{l}\text { TBSA affected } \\
\text { (\%) }\end{array}$ & $\begin{array}{l}\text { LoQ } \\
\text { (ng/mL) }\end{array}$ & $\begin{array}{l}\text { Pimecrolimus } \\
\text { concentration } \\
\text { range (ng/mL) }\end{array}$ \\
\hline Harper et al (2001) 62 & $3 w k$ & $10^{a}$ & $14-53 \mathrm{mo}$ & $23-69$ & 0.5 & $<0.5-1.8$ \\
\hline Allen et al $(2003)^{63}$ & $3 w k$ & $8^{b}$ & $\begin{array}{l}\text { 8-30 mo } \\
\text { (cohort 2) }\end{array}$ & $28-80$ & 0.5 & $<0.5-2.0$ \\
\hline Allen et al $(2003)^{63}$ & $3 w k$ & 8 & $\begin{array}{l}\text { 4-11 mo } \\
\text { (cohort 3) }\end{array}$ & $25-58$ & 0.1 & $<0.1-2.6$ \\
\hline $\begin{array}{l}\text { Lakhanpaul } \\
\text { et al (2002) }\end{array}$ & $\begin{array}{l}49 \text { wk (1-y extension to } \\
\text { Allen et al [2003]) }\end{array}$ & 5 & $5.7-11.9 \mathrm{mo}$ & $39-52$ & 0.1 & $<0.1-1.94$ \\
\hline Staab et al $(2005)^{66}$ & $3 w k$ & 22 & $3.4-22.7 \mathrm{mo}$ & $10-92$ & 0.1 & $<0.1-2.26$ \\
\hline $\begin{array}{l}\text { Eichenfield } \\
\text { et al (2007) }\end{array}$ & $3 w k$ & $17^{c}$ & $3.6-139.2 \mathrm{mo}$ & $10-48$ & 0.1 & $<0.1-0.59^{d}$ \\
\hline
\end{tabular}

Abbreviations: LoQ, limit of quantification; mo, months; TBSA, total body surface area; wk, weeks; y, year.

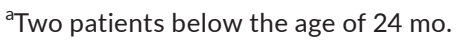

${ }^{\mathrm{b}}$ Three patients below the age of 24 mo with TBSA $>20 \%$.

'Six patients aged between 3 and 23 mo.

${ }^{\mathrm{d}}$ Two samples from the same patient higher than $1 \mathrm{ng} / \mathrm{mL}(2.48$ and $4.14 \mathrm{ng} / \mathrm{mL})$ probably due to contamination of blood samples. 
377.5 days during 2 years of follow-up. ${ }^{68}$ Results demonstrated that topical application of pimecrolimus in infants did not interfere with tetanus, diphtheria, measles, and rubella vaccination response. ${ }^{68}$

Despite numerous studies demonstrating that pimecrolimus was well-tolerated in infants, initial safety and tolerability concerns remained due to the lack of long-term safety data. Therefore, pimecrolimus is in most countries only approved as second-line treatment for short-term use in children with $A D$ above the age of 2 years. Safety concerns were the result of preclinical carcinogenicity studies demonstrating that systemic exposure of animals to immunosuppressant doses of $\mathrm{TCl}$ resulted in malignancies. ${ }^{18,69}$ The preclinical safety concerns were reinforced by cases of lymphoma and skin cancer in patients who were treated systemically with calcineurin inhibitors (cyclosporine and tacrolimus) after whole organ transplantation. These findings ultimately led to the inclusion of a blackbox warning in the US and the second-line use of TCls in Europe which was based on a theoretical rather than a proven risk of malignancy. ${ }^{18,69}$ As described above, systemic exposure to pimecrolimus upon topical application is negligible, even in infants who have the greatest body surface area-to-weight ratio, making it highly unlikely that intermittent or proactive use of pimecrolimus increases the risk for lymphoma or other malignancies later in life. ${ }^{62-64,66}$ Nevertheless, additional safety data were requested mainly to determine the impact of pimecrolimus on the developing immune system, and to counteract the link between pimecrolimus use and (skin) malignancies. Since the implementation of the black-box warning, the 5-year PETITE study, several epidemiological studies, post-marketing surveillance, and the ongoing Pediatric Eczema Elective Registry (PEER), all aimed to resolve these safety concerns. ${ }^{59,70-75}$ The PETITE study reassured that long-term use of topical pimecrolimus in infants was not related to an increased incidence of $18 \mathrm{AEs}$, which were of primary clinical interest because of safety signals reported in previous trials. ${ }^{59}$ Over the 5 -year study period, there were no differences in growth rates between both treatments and not more than $1 \%$ of patients discontinued their treatment. Similar to the results from the vehicle-controlled trials, use of pimecrolimus

TABLE 3 Overview of epidemiological studies evaluating cancer risk associated with different treatments in patients with AD

\begin{tabular}{|c|c|c|c|}
\hline Study & $\begin{array}{l}\text { Number of } \\
\text { patients }\end{array}$ & Results & Conclusion \\
\hline $\begin{array}{l}\text { Arellano } \\
\text { et al }(2007)^{70 a}\end{array}$ & 293253 & $\begin{array}{l}\text { Adjusted OR for lymphoma: } \\
\text { - PIM vs non-use: } 0.82(95 \% \mathrm{Cl} 0.42-1.61) \\
\text { - } \text { TAC vs non-use: } 0.79(95 \% \mathrm{Cl} 0.37-1.71) \\
\text { - low-potency TCS vs non-use: } 1.06(95 \% \mathrm{Cl} \\
\text { 0.72-1.57) } \\
\text { - } \text { high-potency TCS vs non-use: } 1.23(95 \% \mathrm{Cl} \\
\text { 0.83-1.84) }\end{array}$ & $\begin{array}{l}\text { No increased risk of lymphoma in patients treated } \\
\text { with TCS or TCls, including PIM }\end{array}$ \\
\hline Arana et al $(2011)^{74 a}$ & 625915 & $\begin{array}{l}\text { Adjusted OR for lymphoma: } \\
\text { - PIM vs non-use: } 0.76 \text { ( } 95 \% \mathrm{Cl} 0.54-1.08) \\
\text { - } \quad \text { TAC vs non-use: } 1.24 \text { (95\% Cl 0.80-1.91) } \\
\text { - } \quad \text { TCS vs non-use: } 0.90 \text { (95\% Cl 0.75-1.07) }\end{array}$ & $\begin{array}{l}\text { No increased risk of overall lymphoma in patients } \\
\text { with } A D \text { treated with TCS or TCls, including } \\
\text { PIM. No difference in patients below the age of } \\
20 \text { years }\end{array}$ \\
\hline $\begin{array}{l}\text { Schneeweiss } \\
\text { et al }(2009)^{71 b}\end{array}$ & 1200645 & $\begin{array}{l}\text { RR for lymphoma: } \\
\text { - PIM vs non-use: } 1.79 \text { (95\% Cl 0.92-3.48) } \\
\text { - PIM vs TAC: } 1.16 \text { (95\% Cl 0.74-1.82) } \\
\text { - PIM vs TCS: } 1.15 \text { (95\% Cl 0.49-2.72) }\end{array}$ & $\begin{array}{l}\text { No increased risk of lymphoma with PIM } \\
\text { compared to untreated patients or compared to } \\
\text { patients treated with TAC or TCS }\end{array}$ \\
\hline Hui et al (2009) & 953064 & $\begin{array}{l}\text { Adjusted HR for cancer: } \\
\text { - PIM vs non-use: } 1.15 \text { (95\% Cl 0.99-1.31) } \\
\text { - } \quad \text { TAC vs non-use: } 0.93 \text { ( } 95 \% \mathrm{Cl} 0.81-1.07) \\
\text { Adjusted HR for TCL: } \\
\text { - } \quad \text { PIM vs non-use: } 2.32 \text { (95\% Cl 0.89-6.07) } \\
\text { - } \quad \text { TAC vs non-use: } 5.44 \text { (95\% Cl 2.51-11.79) }\end{array}$ & $\begin{array}{l}\text { No increase of overall cancer rate with TAC or } \\
\text { PIM. No increased risk of TCL with PIM. Use of } \\
\text { TAC may be associated with increased risk of TCL }\end{array}$ \\
\hline
\end{tabular}

Abbreviations: $\mathrm{Cl}$, confidence interval; $\mathrm{HR}$, hazard ratio; OR, odds ratio; PIM, pimecrolimus; RR, relative risk; TAC, tacrolimus; TCls, topical calcineurin inhibitors; TCL, T-cell lymphoma; TCS, topical corticosteroids.

${ }^{a}$ Nested case-control study (US PharMetrics database).

${ }^{\mathrm{b}}$ Nested case-control study (US Ingenix database).

${ }^{\mathrm{c}}$ Nested case-control study (UK THIN database).

${ }^{\mathrm{d}}$ Retrospective cohort study (US Kaiser Permanente database). 
FIGURE 1 Lymphoma risk in patients with AD treated with TCls or TCS based on results from a meta-analysis performed by Legendre et al (2015). ${ }^{78} \mathrm{TCls}$, topical calcineurin inhibitors; TCS, topical corticosteroids; $\mathrm{Cl}$, confidence interval

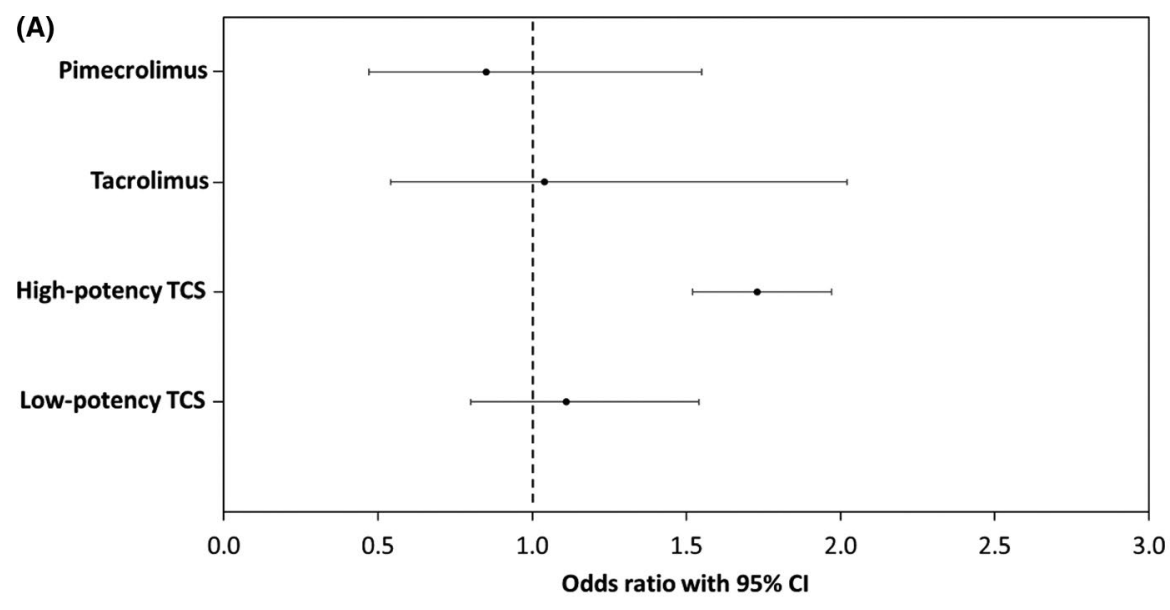

(B)

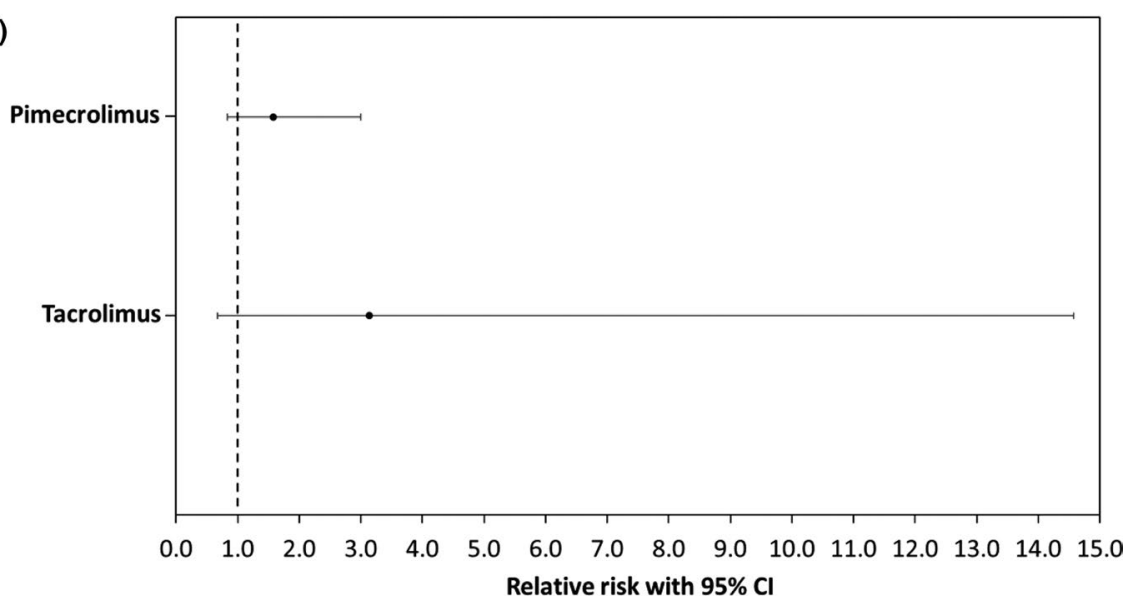

did not affect vaccination response of the infants. Tetanus, hepatitis B, measles, varicella, and Hemophilus influenzae type B antibody titers post-vaccination were all considered normal and comparable between infants who had used pimecrolimus or TCS for the past 5 years. The PETITE study provided additional evidence that use of pimecrolimus has no impact on the developing immune system by demonstrating similar humoral and cellular immune responses with pimecrolimus and TCS. ${ }^{59}$ Furthermore, ex vivo studies showed that levels of CD3 + T-cells over time were comparable not only between pimecrolimus and TCS, but also with historical controls. No malignancies were observed in the pimecrolimus treatment group, and there were no cases of cutaneous T-cell lymphoma or any other skin malignancy in any of the almost 2500 enrolled infants, out of which more than 1000 had used pimecrolimus in the long term. ${ }^{59}$

Additionally, five epidemiological studies were conducted to evaluate the potential malignancy risk that is associated with the use of TCls in general, including pimecrolimus (Table 3). ${ }^{70-72,74,76}$ However, when interpreting results from these studies one should consider that patients with $A D$ are generally more prone to develop cancer compared to patients without AD. This was demonstrated by a study performed in the United Kingdom (UK), comparing more than 60000 patients with $A D$ across all ages with more than 4 million individuals without AD. After adjusting for age and sex, patients with $A D$ had an increased risk to develop cancer in general. ${ }^{77}$ Specifically, AD was found to be associated with increased incidences of lymphoma, melanoma, and nonmelanoma skin cancer (NMSC). ${ }^{77}$ Even when keeping this in mind, none of the five epidemiological studies, involving more than 6.5 million patients with $A D$, showed an increased risk of lymphoma, including T-cell cutaneous lymphoma, in patients with $A D$ who had been treated with pimecrolimus (Table 3). Consistent with these results, a meta-analysis published by Legendre et al $(2015)^{78}$ failed to find a correlation between pimecrolimus and risk of lymphoma when used for the treatment of $A D$ (Figure 1). The same was true for tacrolimus and low-potency TCS, whereas high-potency TCS were associated with a small but significant increase in lymphoma risk (Figure 1). ${ }^{78}$ However, there was a high level of heterogeneity between the included studies and the results for high-potency TCS may have been biased by disease severity, as high-potency TCS are mainly used for the treatment of severe cases, which in itself is a risk factor for lymphoma. ${ }^{70}$ Similarly, there was no association between topical use of pimecrolimus and the incidence of NMSC based on a questionnaire that was sent out to 5000 adult patients with AD out of which 1000 had NMSC. ${ }^{79}$ Interestingly, the latter case-control study reported fewer cases of NMSC in patients treated with $\mathrm{TCls}$, especially with pimecrolimus. ${ }^{79}$

However, epidemiological data are retrospectively collected and patients included in these epidemiological studies often had short or 
unknown exposure times to pimecrolimus without focusing on the pediatric population. Additionally, results obtained from the PETITE study were also limited to a follow-up time of 5 years. Therefore, the PEER was initiated in 2004 to prospectively gather post-marketing data in children with AD between the ages of 2-17 years. ${ }^{73}$ To be included in the registry, children had to be treated for at least 6 weeks with pimecrolimus prior to enrolment into the registry. The primary aim of this nationwide, observational registry in the US and Canada was to evaluate the possible link between topical use of pimecrolimus and malignancy over a follow-up period of 10 years. ${ }^{73}$ At the time of the first interim results, 7457 children with $A D$ were enrolled in the PEER for more than 25000 person-year of follow-up. Over the 10 -year study period, five malignancies had been reported (2 leukemia, 1 osteosarcoma, and 2 lymphomas). ${ }^{73}$ These malignancies were not considered drug-related, and the standardized incidence ratio for all malignancies as compared with the Surveillance, Epidemiology and End Results (SEER) data was 1.2 (95\% Cl 0.5-2.8), indicating that children exposed to pimecrolimus for the treatment of $A D$ are not at risk to develop cancer. ${ }^{73}$ As of March 2020, only five additional cases of malignancies were reported in the PEER, evaluating data derived from 8015 patients and including 45960 person-year of follow-up (Meda data on file). Importantly, neither the interim results nor the latest follow-up data reported any cases of skin cancer. Another registry similarly evaluated the long-term safety of tacrolimus ointment in children with AD. This registry confirmed that there is currently no evidence supportive of an increased long-term cancer risk in children with $\mathrm{AD}$ who had been treated with $\mathrm{TCls}^{80}$ Due to the extensive amount of studies that have been conducted to evaluate the safety of pimecrolimus for the treatment of $A D$ in the pediatric population, data on the long-term use of pimecrolimus are now even surpassing these collected for mid- to high-potency TCS. ${ }^{81}$ Regardless of the treatment, patients with $A D$ are generally at a higher risk to develop lymphoma. Therefore, it cannot be completely excluded at this point that infants will develop lymphoma or other malignancies later in life. Taken together, there is currently no clinical reason to expect malignancies when using topical pimecrolimus for the treatment of $A D$.

\section{6 | CONCLUSIONS}

After nearly 20 years of clinical experience, the Expert Panel concluded that it is no longer appropriate to restrict the use of pimecrolimus to children above the age of 2 years. This is reflected particularly by the recent approval of pimecrolimus for treatment of infants with $A D$ and the removal of the black-box warning in Canada in 2019. ${ }^{82}$ Additionally, the recently published consensus-based European guidelines recommend long-term use of TCls for sensitive skin areas in the pediatric population. ${ }^{15}$ Based on the available evidence and expert opinion, the European Expert Panel concludes that treatment of AD should be initiated as early as infancy, and topical pimecrolimus is a safe and effective steroid-sparing treatment option for both short- and long-term use that should no longer be withheld from infants aged 3 months and above.

\section{ACKNOWLEDGMENTS}

The authors are grateful to Ismar Healthcare NV who provided medical writing assistance on behalf of Meda, a Mylan company.

\section{CONFLICT OF INTEREST}

TL has participated as principal investigator in clinical trials and advisory boards and has given lectures, sponsored by Novartis, Eli Lilly, La Roche Posay, Pfizer, Janssen, and Sanofi. He has received consultancy/speaker honoraria from Novartis, AbbVie, Galderma, La Roche Posay, Mylan, Janssen, and Sanofi and has acted as scientific advisory board member for AbbVie, Celgene, La Roche Posay, Janssen, Pfizer, Menlo, Mylan, Galderma, Symrise, and Lilly. He has received research grants from Celgene, Janssen-Cilag, Leo Pharma, Mylan, and Pfizer. MA has served as a consultant and/or researcher for and/ or has received research grants from AbbVie, ALK-Abelló, Almirall, Amgen, Bayer, Beiersdorf, Biogen, Boehringer Ingelheim, Bristol Myers Squibb, Celgene, Centocor, Dermira, Galderma, Genzyme, GlaxoSmithKline, Hexal, Janssen, LEO, Eli Lilly, Medac, Menlo, MSD, Mylan BV, Novartis, Pfizer, Regeneron, Sandoz, Sanofi, Stallergenes, Trevi, and XenoPort, Inc. JL has participated as principal investigator in clinical trials sponsored by Celgene, LEO Pharma, Galderma, Novartis, and Pfizer. He has received consultancy/speaker honoraria from AbbVie, LEO Pharma, Galderma, Eli Lilly, Janssen-Cilag, La Roche Posay, Pierre Fabre, Bioderma, Novartis, UCB pharma, Meda (a Mylan company), and Celgene. CP has received grants and has been consultant for Almirall, Amgen, AbbVie, BMS, Boehringer, Celgene, Eli Lilly, Merck, Mylan, Novartis, Janssen, Sandoz, Pfizer, LEO Pharma, Merck, Pierre Fabre, Sanofi, and UCB pharma. AT has participated as principal investigator in clinical trials and advisory boards and has given lectures, sponsored by Lilly, Pfizer, Sanofi, AbbVie, Mylan, and Pierre Fabre. CV has participated in clinical trials and advisory boards and given lectures for Novartis, Sanofi, LEO Pharma, AbbVie, Janssen, Eli Lilly, AstraZeneca, and Mylan. He has received grants from Novartis, Sanofi, LEO Pharma, and Pfizer. UW has received consulting/speaker honoraria from Novartis, SanofiAventis, ALK, Berlin-Chemie, Stallergenes, and Mylan. TW has received grants from Novartis, LEO Pharma, AbbVie, and Pfizer and has received personal fees from Novartis, Sanofi-Regeneron, LEO Pharma, Galderma, Lilly, and AbbVie.

\section{AUTHOR CONTRIBUTION}

Thomas Luger: Conceptualization (lead); Writing-original draft (lead); Writing-review \& editing (lead). Matthias Augustin: Conceptualization (equal); Writing-original draft (supporting); Writing-review \& editing (equal). Julien Lambert: Conceptualization (equal); Writing-original draft (supporting); Writing-review \& editing (equal). Carle Paul: Conceptualization (equal); Writing-original draft (supporting); Writing-review \& editing (equal). Carlo Pincelli: Conceptualization (equal); Writing-original draft (supporting); Writing-review \& editing (equal). Antonio Torrelo: Conceptualization (equal); Writing-original draft (supporting); Writing-review \& editing (equal). Christian Vestergaard: Conceptualization (equal); Writingoriginal draft (supporting); Writing-review \& editing (equal). Ulrich 
Wahn: Conceptualization (equal); Writing-original draft (supporting); Writing-review \& editing (equal). Thomas Werfel: Conceptualization (equal); Writing-original draft (supporting); Writing-review \& editing (equal).

\section{PEER REVIEW}

The peer review history for this article is available at https://publo ns.com/publon/10.1111/pai.13422.

\section{ORCID}

Thomas Luger (iD https://orcid.org/0000-0003-1397-1626

\section{REFERENCES}

1. Weidinger S, Novak N. Atopic dermatitis. Lancet. 2016;387(10023):1109-1122.

2. Drucker AM, Wang AR, Li WQ, Sevetson E, Block JK, Qureshi AA. The burden of atopic dermatitis: summary of a report for the National Eczema Association. J Invest Dermatol. 2017;137(1):26-30.

3. Chamlin SL, Chren MM. Quality-of-life outcomes and measurement in childhood atopic dermatitis. Immunol Allergy Clin North Am. 2010;30(3):281-288.

4. Zuberbier T, Orlow SJ, Paller AS, et al. Patient perspectives on the management of atopic dermatitis. J Allergy Clin Immunol. 2006;118(1):226-232.

5. Kapur S, Watson W, Carr S. Atopic dermatitis. Allergy Asthma Clin Immunol. 2018;14(Suppl 2):52.

6. David Boothe W, Tarbox JA, Tarbox MB. Atopic dermatitis: pathophysiology. Adv Exp Med Biol. 2017;1027:21-37.

7. Lyons JJ, Milner JD, Stone KD. Atopic dermatitis in children: clinical features, pathophysiology, and treatment. Immunol Allergy Clin North Am. 2015;35(1):161-183.

8. Yang G, Seok JK, Kang HC, Cho YY, Lee HS, Lee JY. Skin barrier abnormalities and immune dysfunction in atopic dermatitis. Int J Mol Sci. 2020;21(8):2867.

9. Kowalska-Oledzka E, Czarnecka M, Baran A. Epidemiology of atopic dermatitis in Europe. J Drug Assess. 2019;8(1):126-128.

10. Kamer B, Pasowska R, Dolka E, Blomberg A, Rotsztejn H. Prevalence of atopic dermatitis in infants during the first six months of life: authors' observations. Postepy Dermatol Alergol. 2013;30(5):277-281.

11. Thomsen SF. Atopic dermatitis: natural history, diagnosis, and treatment. ISRN Allergy. 2014;2014:354250.

12. Wan J, Mitra N, Hoffstad OJ, Gelfand JM, Yan AC, Margolis DJ. Variations in risk of asthma and seasonal allergies between earlyand late-onset pediatric atopic dermatitis: A cohort study. J Am Acad Dermatol. 2017;77(4):634-640.

13. Mohn $\mathrm{CH}$, Blix HS, Halvorsen JA, Nafstad P, Valberg M, Lagerlov $P$. Incidence trends of atopic dermatitis in infancy and early childhood in a nationwide prescription registry study in Norway. JAMA Netw Open. 2018;1(7):e184145.

14. Kim JP, Chao LX, Simpson EL, Silverberg JI. Persistence of atopic dermatitis (AD): a systematic review and meta-analysis. J Am Acad Dermatol. 2016;75(4):681-687.

15. Wollenberg A, Barbarot S, Bieber T, et al. Consensus-based European guidelines for treatment of atopic eczema (atopic dermatitis) in adults and children: part II. J Eur Acad Dermatol Venereol. 2018;32(6):850-878.

16. Coureau B, Bussières JF, Tremblay S. Cushing's syndrome induced by misuse of moderate- to high-potency topical corticosteroids. Ann Pharmacother. 2008;42(12):1903-1907.
17. Stalder JF, Aubert H, Anthoine E, et al. Topical corticosteroid phobia in atopic dermatitis: international feasibility study of the TOPICOP score. Allergy. 2017;72(11):1713-1719.

18. ELIDEL ${ }^{\circledR}$ (pimecrolimus) Cream, $1 \%$ for topical use; Highlights of prescribing information, 2014. https://www.accessdata.fda.gov/ drugsatfda_docs/label/2014/021302s018lbl.pdf. Accessed 23 June 2020

19. European Medicines Agency. ELIDEL ${ }^{\circledR}$ : Summary of product characteristics. 2006. https://www.ema.europa.eu/en/documents/ referral/elidel-article-31-referral-annex-i-ii-iii_en.pdf.

20. PROTOPIC ${ }^{\circledR}$ (tacrolimus) ointment $0.03 \%$, ointment $0.1 \%$; Prescribing information, 2011. https://www.accessdata.fda.gov/ drugsatfda_docs/label/2011/050777s018lbl.pdf. Accessed 23 June 2020.

21. PROTOPIC ${ }^{\circledR}$ (tacrolimus) ointment $0.03 \%$; Summary of Product Characteristics, 2006. https://www.ema.europa.eu/en/documents/product-information/protopic-epar-product-information en.pdf. Accessed 23 June 2020.

22. Grassberger M, Steinhoff M, Schneider D, Luger TA. Pimecrolimus - an anti-inflammatory drug targeting the skin. Exp Dermatol. 2004;13(12):721-730.

23. Jensen JM, Pfeiffer S, Witt M, et al. Different effects of pimecrolimus and betamethasone on the skin barrier in patients with atopic dermatitis. J Allergy Clin Immunol. 2009;124(3 Suppl 2):R19-R28.

24. Luger T, Boguniewicz M, Carr W, et al. Pimecrolimus in atopic dermatitis: consensus on safety and the need to allow use in infants. Pediatr Allergy Immunol. 2015;26(4):306-315.

25. Davidson WF, Leung DYM, Beck LA, et al. Report from the National Institute of Allergy and Infectious Diseases workshop on "Atopic dermatitis and the atopic march: mechanisms and interventions". J Allergy Clin Immunol. 2019;143(3):894-913.

26. Bergmann RL, Edenharter G, Bergmann KE, et al. Atopic dermatitis in early infancy predicts allergic airway disease at 5 years. Clin Exp Allergy. 1998;28(8):965-970.

27. Gough H, Grabenhenrich L, Reich A, et al. Allergic multimorbidity of asthma, rhinitis and eczema over 20 years in the German birth cohort MAS. Pediatr Allergy Immunol. 2015;26(5):431-437.

28. Flohr C, Perkin M, Logan K, et al. Atopic dermatitis and disease severity are the main risk factors for food sensitization in exclusively breastfed infants. J Invest Dermatol. 2014;134(2):345-350.

29. Brough HA, Liu AH, Sicherer $\mathrm{S}$, et al. Atopic dermatitis increases the effect of exposure to peanut antigen in dust on peanut sensitization and likely peanut allergy. J Allergy Clin Immunol. 2015;135(1):164-170.

30. Hill DA, Grundmeier RW, Ram G, Spergel JM. The epidemiologic characteristics of healthcare provider-diagnosed eczema, asthma, allergic rhinitis, and food allergy in children: a retrospective cohort study. BMC Pediatr. 2016;16:133.

31. Schneider L, Hanifin J, Boguniewicz M, et al. Study of the atopic march: development of atopic comorbidities. Pediatr Dermatol. 2016;33(4):388-398.

32. Brough HA, Simpson A, Makinson K, et al. Peanut allergy: effect of environmental peanut exposure in children with filaggrin loss-offunction mutations. J Allergy Clin Immunol. 2014;134(4):867-875.

33. Newell L, Polak ME, Perera J, et al. Sensitization via healthy skin programs Th2 responses in individuals with atopic dermatitis. J Invest Dermatol. 2013;133(10):2372-2380.

34. Spergel JM, Boguniewicz M, Schneider L, Hanifin JM, Paller AS, Eichenfield LF. Food allergy in infants with atopic dermatitis: limitations of food-specific IgE measurements. Pediatrics. 2015;136(6): e1530-e1538.

35. Roduit C, Frei R, Depner M, et al. Phenotypes of atopic dermatitis depending on the timing of onset and progression in childhood. JAMA Pediatr. 2017;171(7):655-662. 
36. Chalmers JR, Haines RH, Bradshaw LE, et al. Daily emollient during infancy for prevention of eczema: the BEEP randomised controlled trial. Lancet. 2020;395(10228):962-972.

37. Grabenhenrich LB, Keil T, Reich A, et al. Prediction and prevention of allergic rhinitis: a birth cohort study of 20 years. J Allergy Clin Immunol. 2015;136(4):932-940.

38. Barnes KC. Genes and atopic phenotypes. In: Wahn U, Sampson HA eds., Allergy, Immunity and Tolerance in Early Childhood: The First Steps of the Atopic March. Amsterdam, The Netherlands: Elsevier Inc.; 2015:113-131. https://doi.org/10.1016/B978-0-12-42022 6-9.00008-5

39. Brunner PM, Silverberg JI, Guttman-Yassky E, et al. Increasing comorbidities suggest that atopic dermatitis is a systemic disorder. $J$ Invest Dermatol. 2017;137(1):18-25.

40. Ronnstad ATM, Halling-Overgaard AS, Hamann CR, et al. Association of atopic dermatitis with depression, anxiety, and suicidal ideation in children and adults: a systematic review and meta-analysis. J Am Acad Dermatol. 2018;79(448-456):e430.

41. Patel KR, Immaneni S, Singam V, et al. Association between atopic dermatitis, depression, and suicidal ideation: a systematic review and meta-analysis. J Am Acad Dermatol. 2019;80:402-410.

42. Ali F, Vyas J, Finlay AY. Counting the burden: atopic dermatitis and health-related quality of life. Acta Derm Venereol. 2020;100:adv00161.

43. Chamlin SL, Frieden IJ, Williams ML, Chren MM. Effects of atopic dermatitis on young American children and their families. Pediatrics. 2004;114(3):607-611.

44. Zink A, Arents B, Fink-Wagner A, et al. Out-of-pocket costs for individuals with atopic eczema: a crosssectional study in nine European countries. Acta Derm Venereol. 2019;99:263-267.

45. Chung J, Simpson EL. The socioeconomics of atopic dermatitis. Ann Allergy Asthma Immunol. 2019;122(4):360-366.

46. Theodosiou G, Montgomery S, Metsini A, et al. Burden of atopic dermatitis in Swedish adults: a population-based study. Acta Derm Venereol. 2019;99:964-970.

47. Kaufmann R, Folster-Holst R, Hoger P, et al. Onset of action of pimecrolimus cream $1 \%$ in the treatment of atopic eczema in infants. J Allergy Clin Immunol. 2004;114(5):1183-1188.

48. Kapp A, Papp K, Bingham A, et al. Long-term management of atopic dermatitis in infants with topical pimecrolimus, a nonsteroid anti-inflammatory drug. J Allergy Clin Immunol. 2002;110(2):277-284.

49. Papp KA, Werfel T, Folster-Holst R, et al. Long-term control of atopic dermatitis with pimecrolimus cream $1 \%$ in infants and young children: a two-year study. J Am Acad Dermatol. 2005;52(2):240-246.

50. Papp K, Staab D, Harper J, et al. Effect of pimecrolimus cream $1 \%$ on the long-term course of pediatric atopic dermatitis. Int J Dermatol. 2004:43(12):978-983.

51. Ho VC, Gupta A, Kaufmann R, et al. Safety and efficacy of nonsteroid pimecrolimus cream $1 \%$ in the treatment of atopic dermatitis in infants. J Pediatr. 2003;142(2):155-162.

52. Staab D, Kaufmann R, Brautigam M, Wahn U, Group CAC-S. Treatment of infants with atopic eczema with pimecrolimus cream $1 \%$ improves parents' quality of life: a multicenter, randomized trial. Pediatr Allergy Immunol. 2005;16(6):527-533.

53. McKenna SP, Whalley D, de Prost $Y$, et al. Treatment of paediatric atopic dermatitis with pimecrolimus (Elidel, SDZ ASM 981): impact on quality of life and health-related quality of life. J Eur Acad Dermatol Venereol. 2006;20(3):248-254.

54. Forte WC, Sumita JM, Rodrigues AG, Liuson D, Tanaka E. Rebound phenomenon to systemic corticosteroid in atopic dermatitis. Allergol Immunopathol (Madr). 2005;33(6):307-311.

55. Kempers S, Boguniewicz M, Carter E, et al. A randomized investigator-blinded study comparing pimecrolimus cream $1 \%$ with tacrolimus ointment $0.03 \%$ in the treatment of pediatric patients with moderate atopic dermatitis. J Am Acad Dermatol. 2004;51(4):515-525.
56. Paller AS, Lebwohl M, Fleischer AB Jr, et al. Tacrolimus ointment is more effective than pimecrolimus cream with a similar safety profile in the treatment of atopic dermatitis: results from 3 randomized, comparative studies. J Am Acad Dermatol. 2005;52(5):810-822.

57. Huang $\mathrm{X}, \mathrm{Xu} \mathrm{B}$. Efficacy and safety of tacrolimus vs pimecrolimus for the treatment of atopic dermatitis in children: a network meta-analysis. Dermatology. 2015;231(1):41-49.

58. Mandelin JM, Rubins A, Remitz A, et al. Long-term efficacy and tolerability of tacrolimus $0.03 \%$ ointment in infants: ${ }^{*}$ a two-year open-label study. Int J Dermatol. 2012;51(1):104-110.

59. Sigurgeirsson B, Boznanski A, Todd G, et al. Safety and efficacy of pimecrolimus in atopic dermatitis: a 5-year randomized trial. Pediatrics. 2015;135(4):597-606.

60. Gschwind HP, Waldmeier F, Zollinger M, Schweitzer A, Grassberger M. Pimecrolimus: skin disposition after topical administration in minipigs in vivo and in human skin in vitro. Eur J Pharm Sci. 2008;33(1):9-19.

61. Billich A, Aschauer H, Aszodi A, Stuetz A. Percutaneous absorption of drugs used in atopic eczema: pimecrolimus permeates less through skin than corticosteroids and tacrolimus. Int J Pharm. 2004;269(1):29-35.

62. Harper J, Green A, Scott G, et al. First experience of topical SDZ ASM 981 in children with atopic dermatitis. Br J Dermatol. 2001;144(4):781-787.

63. Allen BR, Lakhanpaul M, Morris A, et al. Systemic exposure, tolerability, and efficacy of pimecrolimus cream $1 \%$ in atopic dermatitis patients. Arch Dis Child. 2003;88(11):969-973.

64. Lakhanpaul M, Davies T, Allen BR, Schneider D. Low systemic exposure in infants with atopic dermatitis in a 1-year pharmacokinetic study with pimecrolimus cream 1\%*. Exp Dermatol. 2006;15(2):138-141

65. Eichenfield LF, Ho V, Matsunaga J, Leclerc P, Paul C, Hanifin JM. Blood concentrations, tolerability and efficacy of pimecrolimus cream $1 \%$ in Japanese infants and children with atopic dermatitis. J Dermatol. 2007;34(4):231-236.

66. Staab D, Pariser D, Gottlieb AB, et al. Low systemic absorption and good tolerability of pimecrolimus, administered as $1 \%$ cream (Elidel) in infants with atopic dermatitis-a multicenter, 3-week, open-label study. Pediatr Dermatol. 2005;22(5):465-471.

67. Paul C, Cork M, Rossi AB, Papp KA, Barbier N, de Prost Y. Safety and tolerability of $1 \%$ pimecrolimus cream among infants: experience with 1133 patients treated for up to 2 years. Pediatrics. 2006;117(1):e118-e128.

68. Papp KA, Breuer K, Meurer M, et al. Long-term treatment of atopic dermatitis with pimecrolimus cream $1 \%$ in infants does not interfere with the development of protective antibodies after vaccination. J Am Acad Dermatol. 2005;52(2):247-253.

69. Siegfried EC, Jaworski JC, Hebert AA. Topical calcineurin inhibitors and lymphoma risk: evidence update with implications for daily practice. Am J Clin Dermatol. 2013;14(3):163-178.

70. Arellano FM, Wentworth CE, Arana A, Fernandez C, Paul CF. Risk of lymphoma following exposure to calcineurin inhibitors and topical steroids in patients with atopic dermatitis. J Invest Dermatol. 2007;127(4):808-816.

71. Schneeweiss S, Doherty M, Zhu S, et al. Topical treatments with pimecrolimus, tacrolimus and medium- to high-potency corticosteroids, and risk of lymphoma. Dermatology. 2009;219(1):7-21.

72. Arellano FM, Arana A, Wentworth CE, Fernandez-Vidaurre C, Schlienger RG, Conde E. Lymphoma among patients with atopic dermatitis and/or treated with topical immunosuppressants in the United Kingdom. J Allergy Clin Immunol. 2009;123(5): 1111-1116.

73. Margolis DJ, Abuabara K, Hoffstad OJ, Wan J, Raimondo D, Bilker WB. Association between malignancy and topical use of pimecrolimus. JAMA Dermatol. 2015;151(6):594-599. 
74. Arana A, Wentworth CW, Rivero E, et al. Lymphoma among patients with atopic dermatitis treated with topical corticosteroids and/or topical calcineurin inhibitors [abstract]. J Am Acad Dermatol. 2011;64(2 Suppl 1):AB3.

75. Carr WW. Topical calcineurin inhibitors for atopic dermatitis: review and treatment recommendations. Paediatr Drugs. 2013;15(4):303-310.

76. Hui RL, Lide W, Chan J, Schottinger J, Yoshinaga M, Millares M. Association between exposure to topical tacrolimus or pimecrolimus and cancers. Ann Pharmacother. 2009;43(12):1956-1963.

77. Arana A, Wentworth CE, Fernandez-Vidaurre C, Schlienger RG, Conde E, Arellano FM. Incidence of cancer in the general population and in patients with or without atopic dermatitis in the U.K. Br J Dermatol. 2010;163(5):1036-1043.

78. Legendre L, Barnetche T, Mazereeuw-Hautier J, Meyer N, Murrell D, Paul C. Risk of lymphoma in patients with atopic dermatitis and the role of topical treatment: a systematic review and meta-analysis. J Am Acad Dermatol. 2015;72(6):992-1002.

79. Margolis DJ, Hoffstad O, Bilker W. Lack of association between exposure to topical calcineurin inhibitors and skin cancer in adults. Dermatology. 2007;214(4):289-295.
80. Paller AS, Fölster-Holst R, Chen SC, et al. No evidence of increased cancer incidence in children using topical tacrolimus for atopic dermatitis. J Am Acad Dermatol. 2020;83:375-381.

81. Siegfried EC, Jaworski JC, Kaiser JD, Hebert AA. Systematic review of published trials: long-term safety of topical corticosteroids and topical calcineurin inhibitors in pediatric patients with atopic dermatitis. BMC Pediatr. 2016;16:75.

82. Product monograph including patient medication information Elidel $^{\circledR}$ (Pimecrolimus) Cream, 1\%, 2019. https://pdf.hres.ca/dpd_ pm/00053301.PDF. Accessed 23 June 2020.

How to cite this article: Luger T, Augustin M, Lambert J, et al. Unmet medical needs in the treatment of atopic dermatitis in infants: An Expert consensus on safety and efficacy of pimecrolimus. Pediatr Allergy Immunol. 2020;00:1-11. https:// doi.org/10.1111/pai.13422 